Baseline

\title{
Sediment quality of the Bohai Sea and the northern Yellow Sea indicated by the results of acid-volatile sulfide and simultaneously extracted metals determinations
}

\author{
Xuelu Gao ${ }^{\mathrm{a}, \mathrm{b}, \mathrm{c}, *}$, Jinming Song ${ }^{\mathrm{c}, \mathrm{d}, \mathrm{e}}$, Xuegang $\mathrm{Li}^{\mathrm{c}, \mathrm{d}, \mathrm{e}}$, Huamao Yuan ${ }^{\mathrm{c}, \mathrm{d}, \mathrm{e}}$, Jianmin Zhao ${ }^{\mathrm{a}, \mathrm{c}}$, \\ Qianguo Xing ${ }^{\mathrm{a}, \mathrm{c}}$, Peimiao $\mathrm{Li}^{\mathrm{a}}$ \\ ${ }^{a}$ CAS Key Laboratory of Coastal Environmental Processes and Ecological Remediation, Yantai Institute of Coastal Zone Research, Chinese Academy of Sciences, Yantai, \\ Shandong 264003, China \\ ${ }^{\mathrm{b}}$ University of Chinese Academy of Sciences, Beijing 100049, China \\ ${ }^{\mathrm{c}}$ Center for Ocean Mega-Science, Chinese Academy of Sciences, Qingdao, Shandong 266071, China \\ ${ }^{\mathrm{d}}$ CAS Key Laboratory of Marine Ecology and Environmental Sciences, Institute of Oceanology, Chinese Academy of Sciences, Qingdao 266071, China \\ ${ }^{\mathrm{e}}$ Laboratory for Marine Ecology and Environmental Sciences, Qingdao National Laboratory for Marine Science and Technology, Qingdao 266237, China
}

\section{A R T I C L E I N F O}

\section{Keywords:}

Toxic trace metals

Geochemical form

Potential mobility

Sediment analysis

Sediment quality indicator

Biological risk

\begin{abstract}
A B S T R A C T
The surface sediments from the Bohai Sea (BS) and the northern Yellow Sea (NYS) were analyzed for acidvolatile sulfide (AVS) and simultaneously extracted metals (SEM) to assess the sediment quality. The results indicated that $>60 \%$ of the samples were found to have possible adverse effects on aquatic life in the BS based on the difference between the concentrations of AVS ([AVS]) and SEM ([SEM]), and the corresponding percentage in the NYS was $<25 \%$. Nevertheless, there was no indication of adverse effects for all the BS and the NYS samples when the total organic carbon (TOC) concentration was introduced in the sediment quality evaluation with [AVS] and [SEM]. The grain size composition, TOC, water content and $\mathrm{pH}$ all had significant influence on the distribution of [SEM] and the [SEM]/[AVS] ratios; while, in contrast, the distribution of [AVS] could be mainly determined by the redox condition of sediment.
\end{abstract}

Trace metals as ubiquitous environmental contaminants are of a major concern for ecological protection because they are toxic to living organisms when their concentrations are over certain thresholds. One of the most serious environmental risks of these metals differentiating them from other toxic pollutants is that they are non-biodegradable and could be bioaccumulated and biomagnified, which makes them a potential threat to the health of organisms or even human beings through the food chain (Bryan et al., 1979; Wang, 2002). Huge amounts of anthropogenically discharged trace metals entering the sea result from river inputs of domestic sewage, agricultural fertilizers, untreated industrial and municipal wastewater and so on (Pan and Wang, 2012). Sediments as a sink are often the ultimate receptacle of these anthropogenic trace metals in aquatic ecosystems; however, when environmental conditions change, they could turn into a source of trace metals (van den Berg et al., 1999; Wilson and Chang, 2000; Sahuquillo et al., 2003).

Acid-volatile sulfide (AVS) is operationally defined as the reactive sulfide fraction that can be volatilized by $1 \mathrm{M}$ or $6 \mathrm{M}$ cold hydrochloric acid extraction (Rickard and Morse, 2005), and it is one of the major chemical constituents that control the environmental risks of trace metals in aquatic sediments (Di Toro et al., 1990, 1992; Prica et al., 2008). Dissolved free sulfides can react with several divalent transition metal cations to form highly insoluble metal sulfides in sediments that are no longer bioavailable to benthic organisms (Di Toro et al., 1992; Allen et al., 1993; Ankley et al., 1996; Berry et al., 1996; USEPA, 2004). The concentrations of toxic metals in sediment pore water will be very low, therefore posing little environmental risks if the amount of sulfide sources is sufficient. On the contrary, it has been proved that divalent transition metals do begin to cause toxicity in sediment if the reservoir of sulfide sources is used up (Di Toro et al., 1990). Therefore, AVS in sediments has received much attention in the past decades in environmental monitoring and assessment (e.g. Di Toro et al., 1992; Ankley et al., 1996; USEPA, 2004; Prica et al., 2008; Gao et al., 2013; Zhuang and Gao, 2013; Li et al., 2014a, 2014b; Pignotti et al., 2018;

\footnotetext{
* Corresponding author at: CAS Key Laboratory of Coastal Environmental Processes and Ecological Remediation, Yantai Institute of Coastal Zone Research, Chinese Academy of Sciences, Yantai, Shandong 264003, China.

E-mail address: xlgao@yic.ac.cn (X. Gao).
} 
Wang et al., 2019; Chen et al., 2020).

The purge-and-trap method (e.g. Allen et al., 1993; van den Hoop et al., 1997; Fang et al., 2005; Gao et al., 2013) and the diffusion method (e.g. Hsieh and Yang, 1989; Hsieh and Shieh, 1997; van Griethuysen et al., 2002; Ye et al., 2011) are the most widely used methods for AVS extraction. Compared with the purge-and-trap method, the diffusion method has the advantages of saving labor and time when relatively large numbers of samples are processed. Besides, researchers have verified that the diffusion method has higher efficiency in AVS extraction than the purge-and-trap method (Brouwer and Murphy, 1994; Leonard et al., 1996; van Griethuysen et al., 2002).

The sulfide-bound metals, such as cadmium (Cd), copper (Cu), lead $(\mathrm{Pb})$, nickel $(\mathrm{Ni})$ and zinc $(\mathrm{Zn})$, extracted during the AVS extraction process are called "simultaneously extracted metals" (SEM) (USEPA, 2004). The relationship between the molar concentrations of AVS ([AVS]) and SEM ([SEM]) has been proposed as a possible indicator of assessing the ecological risk of metals in sediments (Ankley et al., 1996; van den Hoop et al., 1997; Long et al., 1998; USEPA, 2004, 2005).

The Bohai Sea Economic Rim covers the entire coast of the Bohai Sea and the coast of the Yellow Sea in Shandong and Liaoning provinces in northern China, making it one of the three most densely populated and industrialized zones in northern China. Rapid expansion of agricultural, industrial and aquacultural activities in this area, with simultaneous development in the construction of harbors, transportation and tourism, has resulted in a significant anthropogenic increase in the ambient levels of pollution and environmental pressure in the marine ecosystem of the Bohai Sea (BS) and the northern Yellow Sea (NYS) (Zhang et al., 2010; Gao et al., 2014, 2015). The aim of this study is to assess the status of sediment quality based on the analysis of AVS and SEM in surface sediments of the BS and the NYS.

The survey in this study was carried on board R/V Dongfanghong II in the Bohai Sea and the northern Yellow Sea during the period 2-11 July 2013 (Fig. 1). All materials that were utilized for sampling, treatment and storage were carefully chosen and properly treated to minimize anthropogenic contamination of the samples. Sampling was carried out using a stainless steel box sampler. One sample was collected with a plastic spatula from the sampler at each sampling site and a total of 26 undisturbed surface sediment samples (top 0-5 cm) were obtained, among which half were from the BS and the other half were from the NYS (Fig. 1). Immediately after being taken, each sample was packed in an acid-rinsed polyethylene bottle that was full of high-purity nitrogen gas without headspace, and stored in a refrigerator at $-18{ }^{\circ} \mathrm{C}$ for future analyses.

In case of being oxidized by oxygen, the determination of $\mathrm{pH}$ and redox potential $(\mathrm{Eh})$ of sediments was operated in situ immediately after sampling with $\mathrm{pH}$ and redox electrodes, respectively. The sample granulometry was analyzed using a Malvern Mastersizer 2000 laser diffractometer with the capacity of analyzing particle sizes between 0.02 and $2000 \mu \mathrm{m}$. The percentages of the following three groups of grain sizes were determined: $<4 \mu \mathrm{m}$ (clay), 4-63 $\mu \mathrm{m}$ (silt), and $>63 \mu \mathrm{m}$ (sand). The water contents of sediments were determined gravimetrically by comparing the weight difference before and after heating an aliquot of each sample at $105{ }^{\circ} \mathrm{C}$ to a constant mass. The percentages of water were used to convert substance contents of sediments from wet to dry weight base. The concentrations of TOC in sediments were determined by an Elementar vario MACRO cube CHNS analyzer on the aliquots of samples that had been removed the inorganic carbon with $1 \mathrm{M} \mathrm{HCl}$, and the analytical precision was better than $\pm 5 \%$ based on replicated analyses.

In this study, AVS was extracted by the diffusion method referenced and combining the reports of Hsieh and Yang (1989), Leonard et al. (1996) and van Griethuysen et al. (2002), within two weeks after sample collection (Lasorsa and Casas, 1996). The extraction was carried out in $125 \mathrm{ml}$ three-necked flasks in which the reaction was conducted. $10 \mathrm{ml}$ of sulfide antioxidant buffer (SAOB) solution was added to a flatbottomed tall plastic vial, and then the vial was inserted into a flask and fixed at the place $\sim 25 \mathrm{~mm}$ above its bottom of the flask. The SAOB solution was prepared by mixing $2 \mathrm{M} \mathrm{NaOH}, 0.2 \mathrm{M}$ ascorbic acid and $0.2 \mathrm{M}$ disodium EDTA. Close the flask with rubber stoppers, one of which has two independent glass gas delivery tubes, and purge the flask with high-purity nitrogen gas for $5 \mathrm{~min}$ to squeeze out internal oxygen. About $3 \mathrm{~g}$ of a wet sediment sample was added to the reaction apparatus. Then $10 \mathrm{ml}$ of $6 \mathrm{M} \mathrm{HCl}$ solution was injected quickly to initiate the reaction and the apparatus was sealed up. A magnetic stirrer working at a moderate stirring rate was used to allow a better mixing. The reaction was allowed to proceed for $\sim 24 \mathrm{~h}$ at room temperature to ensure the generated hydrogen sulfide $\left(\mathrm{H}_{2} \mathrm{~S}\right)$ was fully absorbed into the absorbing liquid in which the amount of free sulfur ions was measured with a sulfide ion selective electrode. After extraction, the sediment suspension was kept stationary for a while, then the supernatant was filtered through a pre-cleaned $0.45 \mu \mathrm{m}$ membrane, and the concentrations of SEM in the filtrate were determined by inductively coupled plasma optical emission spectrometry on a PerkinElmer Optima 7000 DV spectrometer. All results were expressed based on the dry weight of the sediments.

All glassware and plasticware used in the experiment were precleaned by soaking in $5 \% \mathrm{HNO}_{3}(v / v)$ for at least $48 \mathrm{~h}$, followed by soaking and rinsing with $18.2 \mathrm{M} \Omega$-cm deionized water. All of the chemicals were guaranteed reagent grade, and all experimental solutions were made up by using deoxygenated deionized water. Apparatus blanks, calibration curves, reagent blanks, and standard recoveries were employed in the analysis. For duplicate measurements, the relative

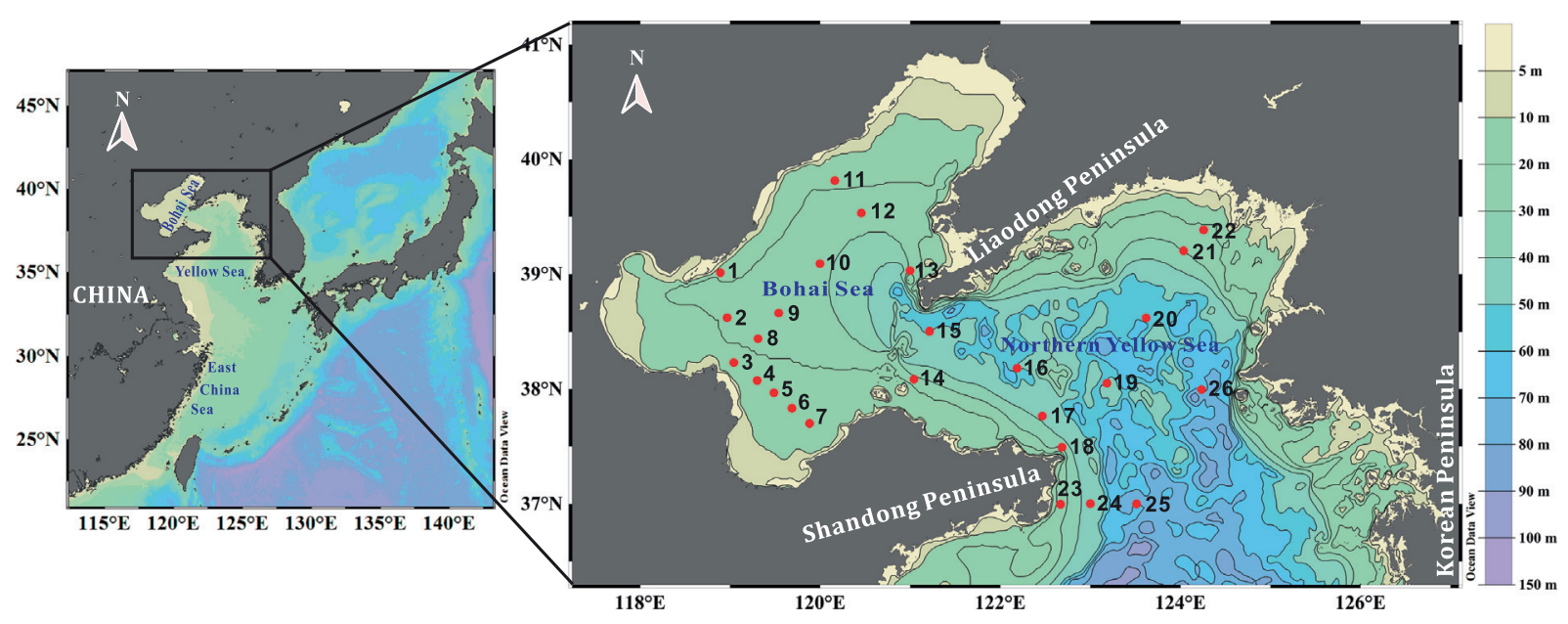

Fig. 1. Location of sampling sites in the BS and the NYS, China. 

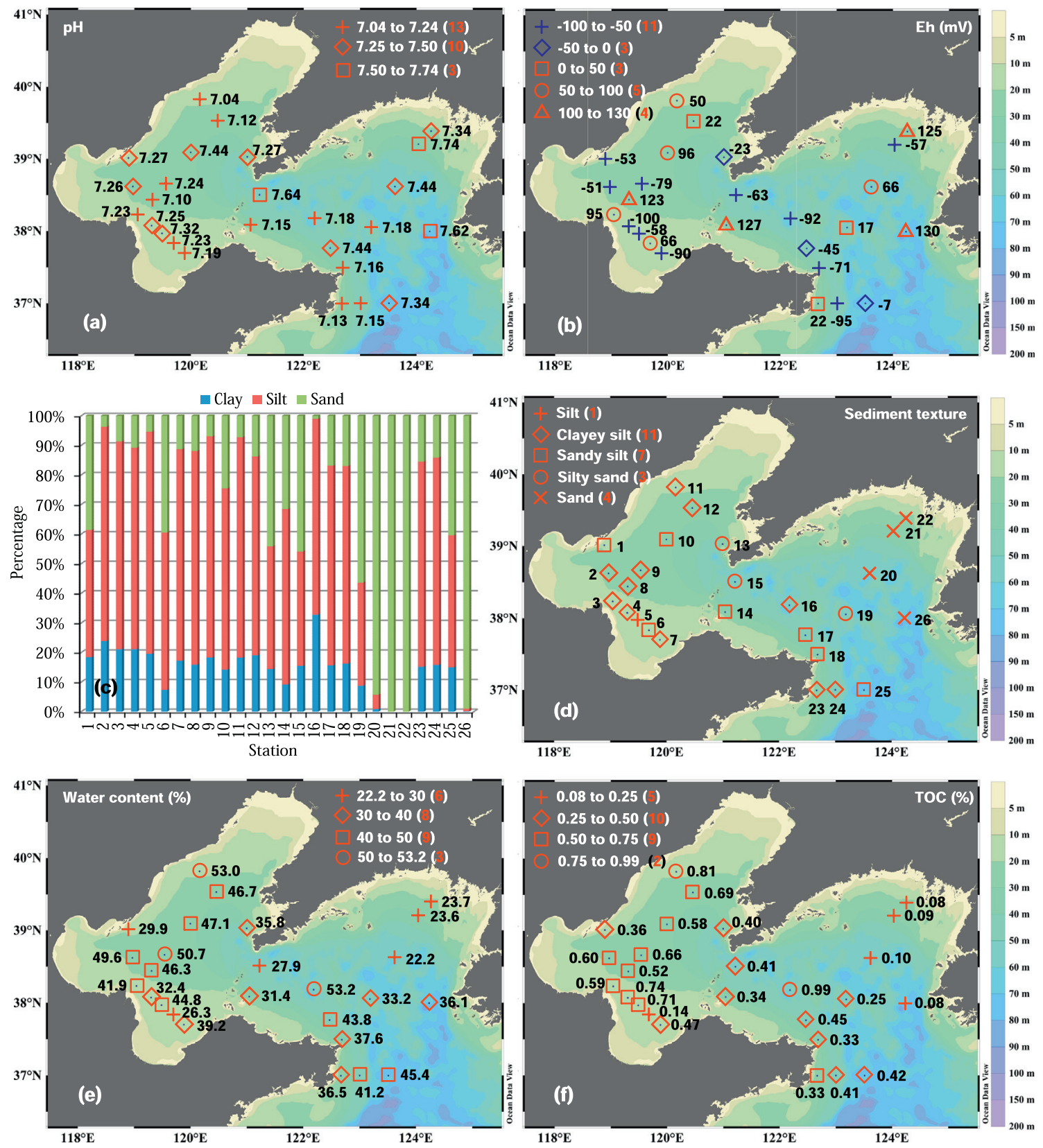

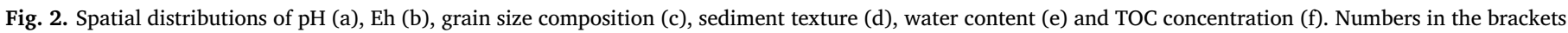
denote that the amounts of data fell into different categories.

standard deviations of the AVS- and SEM-contents were found to be within $10 \%$. The recovery of the experimental method, checked using sodium sulfide solution with a known concentration, was better than $90 \%$. The detection limit for the sulfide measurement method was $0.13 \mu \mathrm{mol} \mathrm{g}^{-1}$.

In this study, $\mathrm{pH}$, Eh, grain size, water content and TOC concentration were measured to obtain the general characteristics of the surface sediment samples. As displayed in Fig. 2a, the sediment pH values in half of the sampling sites fell in the range of 7.04-7.25 and in 10 of the 26 sampling sites fell in the range of 7.25-7.50, and it was only in three sampling sites that the sediment $\mathrm{pH}$ values were higher than 7.5. Comparatively, the range of $\mathrm{pH}$ values in the surface sediments of the BS was narrower than that of the NYS; $\mathrm{pH}$ varied from 7.04 to 7.44 with an average of 7.23 in the BS, and the corresponding data were 7.13-7.74 and 7.35 in the NYS, respectively.

Eh is a parameter that is usually measured to characterize the oxidation-reduction status of surface environments in geochemical and related studies. The redox conditions in sediments could reflect the degree of organic enrichment, and the organic enrichment of sediments usually leads to reduced conditions. Reflected by their Eh values, the studied samples were in the anaerobic reduced condition (Fig. 2b). The number of the sampling sites with negative Eh values was slightly higher than that of the sampling sites with positive Eh values, and the sediments in $>2 / 5$ of the sampling sites had the Eh value of $<-50$ $\mathrm{mV}$ (Fig. 2b). The sediments of the BS had comparable Eh values with those of the NYS; Eh varied from -100 to $123 \mathrm{mV}$ with an average of $0 \mathrm{mV}$ in the surface sediments from the BS, and the corresponding data were -95 to $130 \mathrm{mV}$ and $4 \mathrm{mV}$ in the NYS, respectively. The sampling sites in the BS and the NYS had an equal number of positive or negative Eh values.

As shown in Fig. 2c, the spatial difference in sediment grain size composition in the BS was smaller than that in the NYS. On the whole, the studied surface sediments of the BS were mainly composed of silt fraction, followed by much less but very similar contents of sand and 
clay fractions; the studied surface sediments of the NYS were predominantly composed of roughly comparable contents of sand and silt fractions, and on average the clay fraction only accounted for $63.6 \%$ of that of the BS. For the studied sediments of the BS, the clay fraction varied from $7.4 \%$ to $23.9 \%$ with an average of $17.6 \%$, the silt fraction ranged from $41.4 \%$ to $75.1 \%$ with an average of $65.0 \%$, and the sand fraction varied from $3.7 \%$ to $44.2 \%$ with an average of $17.4 \%$. For those of the NYS, the corresponding ranges of clay, silt and sand fractions were $0 \%-32.8 \%, 0 \%-70.0 \%$ and $1.1 \%-100 \%$, respectively, with their respective averages of $11.2 \%, 40.2 \%$ and $48.6 \%$. According to the classification of Shepard (1954), nearly $70 \%$ of the samples were clayey silt and sandy silt; the surface sediments of the BS were mainly classified as clayey silt followed by sandy silt, and the surface sediments of the NYS were mainly classified as sand and sandy silt followed by clayey silt (Fig. 2d). It could also be seen from Fig. 2d that the finer sediments, i.e. silt and clayey silt, were generally from the sampling sites with shallower water depths of $<30 \mathrm{~m}$, and the sampling sites with deeper water depths of $>30 \mathrm{~m}$ were dominated by the coarser sediments, i.e. sandy silt, silty sand and sand.

On average, the surface sediments of the BS had higher water contents than those of the NYS, which was readily understandable because of the higher average percentages of the finer fractions (clay + silt) of sediments of the former, but they had approximately similar ranges of water contents. As shown in Fig. 2e, the water contents in the surface sediments of the BS and the NYS varied within $26.3-53.0 \%$ and $22.2-53.2 \%$ with the average values of $41.8 \%$ and $35.0 \%$, respectively. The water contents in about $65 \%$ of the samples varied within the range of $30-50 \%$; the higher values of $>40 \%$ were mainly recorded in the BS and the lower values of $<40 \%$ were mainly recorded in the NYS (Fig. 2e).

It could be seen from Fig. $2 \mathrm{f}$ that the higher TOC contents of $>0.5 \%$ were dominantly recorded in the BS and the lower TOC contents of $<0.50 \%$ were dominantly recorded in the NYS. This was because the BS had finer components of sediments than that of the NYS and finer sediments are beneficial for the preservation of TOC. It could also be seen that the TOC contents in over $70 \%$ samples were in the range of $0.25-0.75 \%$; only in two of 26 samples, one from the BS and the other from the NYS, the TOC contents were $>0.75 \%$; in five of the 26 samples, among which four were from the NYS, the TOC contents were $<0.25 \%$ (Fig. 2f). The TOC contents varied from $0.14-0.81 \%$ with an average of $0.56 \%$ in the BS, and the corresponding data were $0.08 \%$ to $0.99 \%$ and $0.33 \%$ in the NYS (Fig. 2 f). The spatial variation in TOC contents in the NYS was wider than that in the BS (Fig. 2f).

The spatial distribution of [AVS] in the surface sediments of the BS and the NYS is shown in Fig. 3a and summarized in Table 1. The AVS concentrations varied within the range of 0.39 to $3.99 \mu \mathrm{mol} \mathrm{g}^{-1}$ in the BS with a mean of $1.25 \mu \mathrm{mol} \mathrm{g}^{-1}$, and they varied within a wider range of 0.28 to $5.13 \mu \mathrm{mol} \mathrm{g}^{-1}$ in the NYS with a mean of $1.40 \mu \mathrm{mol} \mathrm{g} \mathrm{g}^{-1}$. Both in the BS and the NYS, relatively lower AVS concentrations of $<$ $1 \mu \mathrm{mol} \mathrm{g}^{-1}$ were measured at 8 of the 13 sites; relatively higher AVS concentrations of $>2 \mu \mathrm{mol} \mathrm{g}^{-1}$ were measured only at 5 sites, $<20 \%$ of the total amount of the sampling sites, among which 2 were in the BS and 3 were in the NYS (Fig. 3a).

It has been proved that sulfate reducing bacteria (SRB) play a vital role in the process of AVS formation (Rickard and Morse, 2005). Generally, more fine sediment fractions (clay + silt), less coarse sediment fraction (sand) and oxidation of TOC could provide a relatively more anoxic environment for SRB to reduce sulfate to sulfide, favoring the accumulation of AVS in sediments (van den Berg et al., 1999; Machado et al., 2008; Du et al., 2011). However, [AVS] was significantly correlated with none of the clay, silt, sand and TOC content in this study (Table 2), which might be owing to the fact that, in addition to the processes occurring in sediment, the hydrodynamic and biogeochemical conditions of the overlying water are also important influencing factors for the [AVS] in sediments; yet the spatial distribution of [AVS] in sediments was still determined by their redox condition reflected by the significant negative correlation between [AVS] and Eh values (Table 2). Fang et al. (2005) and Liu et al. (2007) also reported that no significant correlation was found between [AVS] and TOC content in their research. Our previous study also indicated that [AVS] had no significant correlation with the clay, silt and sand fractions of sediments (Gao et al., 2013).

The AVS concentrations in this study were lower than most of the previous reported data for the other Chinese coastal areas in the Bohai and Yellow Seas that face strong interference of human activities, such as the Jinzhou Bay, the Bohai Bay, the Laizhou Bay, the coastal waters of the Zhangzi Island, the Rushan Bay and the Jiaozhou Bay (Table 1). In addition, it is noteworthy that the mean AVS concentrations of the BS and the NYS in this study were higher than those of the Yellow River Estuary and its adjacent coastal waters. Marine sediment usually contains more sulfate than freshwater sediment does, and sulfate reduction is a key process in AVS formation in marine sediment (Hansen et al., 1996; van den Berg et al., 1999). Therefore, it seems reasonable to conjecture that, compared with the results in this study, the lower AVS concentration in the sediments of the Yellow River Estuary and its adjacent coastal waters was due to the dilution of sedimentary sulfate caused by the discharge of suspended sediments with lower sulfate content from the Yellow River.

The SEM concentrations in the surface sediments of the BS varied within the range of 0.54 to $1.46 \mu \mathrm{mol} \mathrm{g}^{-1}$ with a mean of $1.05 \mu \mathrm{mol} \mathrm{g}^{-1}$ (Table 1). In the NYS, the SEM concentrations ranged from 0.09 to $1.26 \mu \mathrm{mol} \mathrm{g}^{-1}$ with a mean of $0.58 \mu \mathrm{mol} \mathrm{g}^{-1}$ (Table 1). There were 5 sites, all of which were in the northeastern NYS, that had the lower values of 0 to $0.5 \mu \mathrm{mol} \mathrm{g}^{-1}$; three fourth of the 12 higher values of 1 to $1.5 \mu \mathrm{mol} \mathrm{g}^{-1}$ were recorded in the BS (Fig. 3b).

The highest [SEM] value obtained in this study was $1.46 \mu \mathrm{mol} \mathrm{g}^{-1}$, which was apparently lower than those obtained in other coastal BS areas; its maximum value in literature was $2.96 \mu \mathrm{mol} \mathrm{g}^{-1}$ in the Bohai Bay and up to $374 \mu \mathrm{mol} \mathrm{g}^{-1}$ in the Jinzhou Bay (Table 1). Although [SEM] spatially varied within a wider range, its mean value in the NYS in this study was comparable to and just slightly higher than that of the Laizhou Bay and the coastal waters of the Zhangzi Island; the mean [SEM] value in the BS was comparable to that of the Yellow River Estuary and its adjacent coastal waters (Table 1).

As that of our previous research in the Laizhou Bay of the Bohai Sea and the coastal waters around the Zhangzi Island of the northern Yellow Sea (Gao et al., 2013), the data in this study showed an insignificant correlation between [AVS] and [SEM] (Table 2). Excluding [AVS], the spearman correlation analysis showed that the [SEM] were significantly correlated with all the other parameters in Table 2 except Eh, revealing that they were potential influencing factors for the spatial distribution of [SEM]. That is to say, more fine sediment fractions (clay + silt), less of the coarse sediment fraction (sand), higher TOC and water contents and lower $\mathrm{pH}$ favored the accumulation of SEM in the surface sediments of the BS and the NYS.

The predominance of $\mathrm{Zn}$ over all the other acid-extracted metals was evident in all samples except the one from the sampling site 19 (Fig. 4). Zn accounted for an average of $\sim 54 \%$ of [SEM], whereas much more toxic Cd contributed no $>0.8 \%$ to [SEM]. In the BS, the percentage contributions of $\mathrm{Cd}, \mathrm{Cu}, \mathrm{Ni}, \mathrm{Pb}$ and $\mathrm{Zn}$ to [SEM] varied in the ranges of $0.04-0.13 \%, 15.4-24.0 \%, 14.8-21.8 \%, 6.3-7.5 \%$ and $50.1-63.0 \%$ with the average values of $0.07 \%, 19.9 \%, 18.5 \%, 6.9 \%$ and $54.7 \%$, respectively; in the NYS, they varied in the ranges of $0.03-0.72 \%, 7.3-25.0 \%, 12.9-38.4 \%, 3.8-15.5 \%$ and $33.4-67.1 \%$ with the average values of $0.14 \%, 16.7 \%, 21.1 \%, 8.6 \%$ and $53.5 \%$, respectively. On average, the concentrations of the acid-extracted trace metals increased in the order $\mathrm{Cd}<<\mathrm{Pb}<\mathrm{Ni}<\mathrm{Cu}<\mathrm{Zn}$ in the $\mathrm{BS}$ (Table 1), which was consistent with that in both the Laizhou Bay and the coastal waters of the Zhangzi Island (Gao et al., 2013); they followed the order $\mathrm{Cd}<<\mathrm{Pb}<\mathrm{Cu}<\mathrm{Ni}<\mathrm{Zn}$ in the NYS (Table 1). The studied trace metals were significantly correlated with each other indicating a common source (Table 2). Their significant correlations 

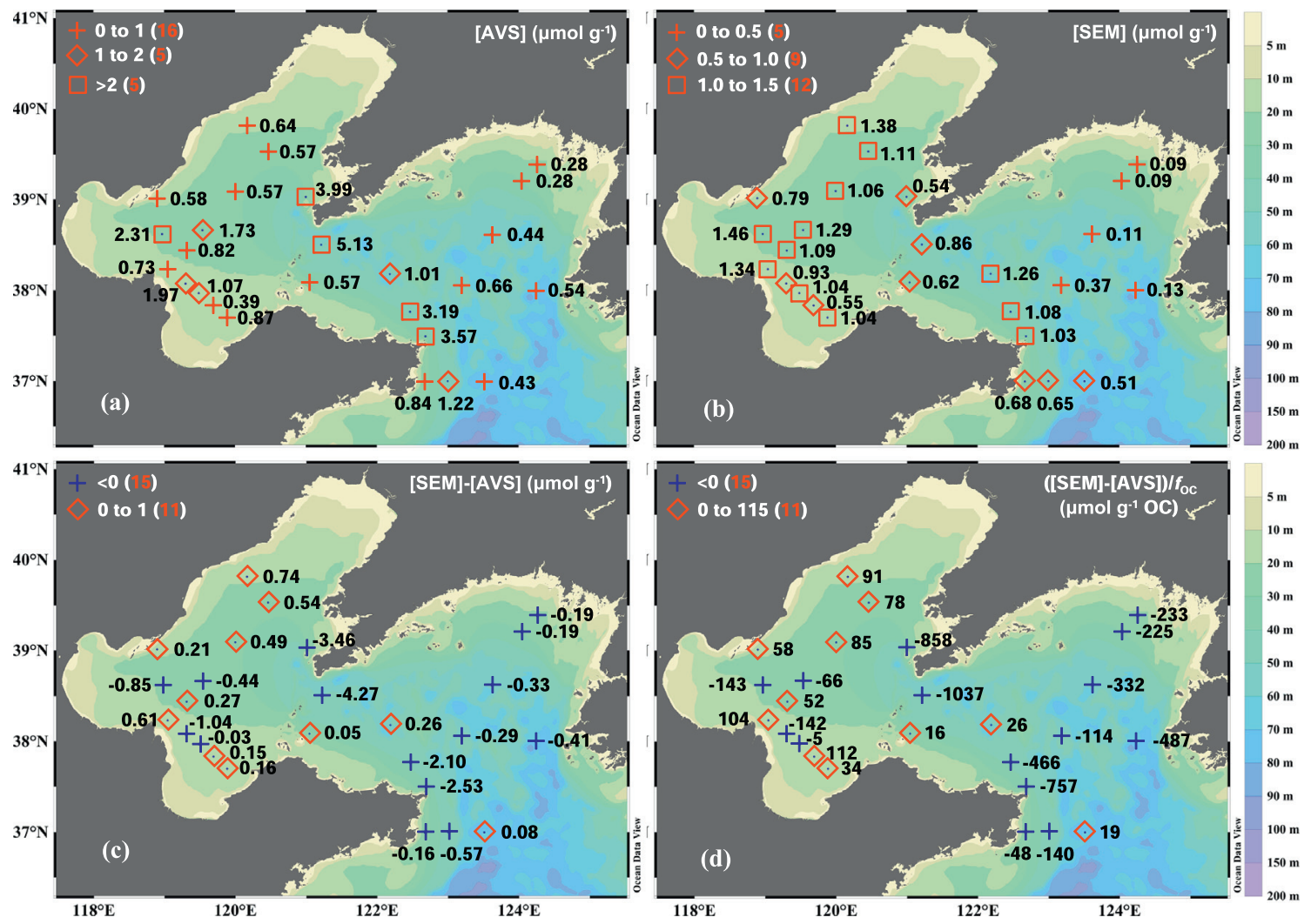

Fig. 3. Spatial variations in [AVS] (a), [SEM] (b), [SEM] - [AVS] (c) and ([SEM] - [AVS])/ $f_{\text {oC }}$ (d). Numbers in the brackets denote that the amounts of data fell into different categories.

with the environmental parameters in Table 2 revealed that the grain size composition, TOC and water content all were important influencing factors for each of the SEM components, and this was also the condition of $\mathrm{pH}$ for all of the 5 metals except $\mathrm{Cd}$; while Eh seemed to have no influence on any of them.
Metal accumulation due to anthropogenic activities is ubiquitous in aquatic environments. Metals exist in sediments in various geochemical fractions, and AVS is one of the important binding phases that influence the mobility and bioavailability of metals. The concentrations of metals in sediment pore water will be very low if the sulfide ions are in

Table 1

Summary of [AVS], [SEM] and acid-extracted metal contents in surface sediments collected from NYS and BS. Related values reported for surface sediments of other coastal areas of China are shown for comparison. The unit is $\mu \mathrm{mol} \mathrm{g}^{-1}$ dry sediment weight for all parameters, and $[\mathrm{SEM}]=[\mathrm{SEM}]_{\mathrm{Cd}}+[\mathrm{SEM}]_{\mathrm{Ni}}+[\mathrm{SEM}]_{\mathrm{Cu}}+[\mathrm{SEM}]_{\mathrm{Pb}}+[\mathrm{SEM}]_{\mathrm{Zn}}$.

\begin{tabular}{|c|c|c|c|c|c|c|c|c|c|}
\hline Location & & [AVS] & [SEM] & {$[\mathrm{SEM}]_{\mathrm{Cd}}$} & {$[\mathrm{SEM}]_{\mathrm{Cu}}$} & {$[\mathrm{SEM}]_{\mathrm{Ni}}$} & {$[\mathrm{SEM}]_{\mathrm{Pb}}$} & {$[\mathrm{SEM}]_{\mathrm{Zn}}$} & Reference \\
\hline \multirow[t]{2}{*}{ Bohai Sea } & Range & $0.39-3.99$ & $0.54-1.46$ & $0.0002-0.0017$ & $0.091-0.308$ & $0.096-0.273$ & $0.037-0.099$ & $0.289-0.782$ & Present study \\
\hline & Mean & 1.25 & 1.05 & 0.0007 & 0.211 & 0.192 & 0.071 & 0.572 & \\
\hline \multirow[t]{2}{*}{ Northern Yellow Sea } & Range & $0.28-5.13$ & $0.09-1.26$ & BDL-0.0010 & $0.009-0.251$ & $0.015-0.246$ & $0.012-0.086$ & $0.050-0.681$ & Present study \\
\hline & Mean & 1.40 & 0.58 & 0.0004 & 0.105 & 0.124 & 0.039 & 0.308 & \\
\hline \multirow[t]{2}{*}{ Laizhou Bay } & Range & $1.22-7.60$ & $0.20-0.74$ & $0.0011-0.0033$ & $0.051-0.310$ & $0.033-0.138$ & $0.014-0.097$ & $0.064-0.278$ & Gao et al., 2013 \\
\hline & Mean & 2.99 & 0.45 & 0.0020 & 0.166 & 0.074 & 0.044 & 0.165 & \\
\hline \multirow[t]{2}{*}{ Coastal waters of the Zhangzi Island } & Range & $0.71-11.03$ & $0.10-0.57$ & BDL-0.0013 & $0.026-0.247$ & $0.013-0.046$ & $0.010-0.067$ & $0.052-0.216$ & Gao et al., 2013 \\
\hline & Mean & 4.05 & 0.32 & 0.0007 & 0.109 & 0.034 & 0.039 & 0.137 & \\
\hline \multirow[t]{2}{*}{ SW Coastal Laizhou Bay } & Range & $0.70-20.5$ & $0.23-0.82$ & $0.0001-0.0014$ & $0.029-0.243$ & $0.047-0.190$ & $0.005-0.066$ & $0.077-0.396$ & $\begin{array}{l}\text { Zhuang and Gao, } \\
2013\end{array}$ \\
\hline & Mean & 4.30 & 0.40 & 0.0006 & 0.088 & 0.105 & 0.026 & 0.184 & \\
\hline \multirow[t]{2}{*}{ Coastal Bohai Bay and Laizhou Bay } & Range & $0.05-5.8$ & $0.3-3.2$ & & & & & & Li et al., 2014a \\
\hline & Mean & 0.73 & 0.99 & & & & & & \\
\hline $\begin{array}{l}\text { Coastal waters around the Yellow River } \\
\text { Estuary }\end{array}$ & Mean & 0.38 & 0.56 & & & & & & Li et al., 2014b \\
\hline \multirow[t]{2}{*}{ Yellow River Estuary } & Range & $0.15-1.85$ & $0.90-1.86$ & $0.184-0.376$ & $0.212-0.404$ & & $0.017-0.033$ & $0.438-1.228$ & Wu et al., 2007 \\
\hline & Mean & 0.94 & 1.33 & 0.022 & 0.289 & & 0.230 & 0.764 & \\
\hline Jinzhou Bay & Range & $3.02-126$ & $2.9-374$ & & & & & & Hansen et al., 1996 \\
\hline \multirow[t]{2}{*}{ Jiaozhou Bay } & Range & $5.06-19.11$ & & & & & & & Huo et al., 2001 \\
\hline & Mean & 11.41 & & & & & & & \\
\hline Licunhe Estuary, Jiaozhou Bay & Range & $0.43-29.45$ & & & & & & & Yu et al., 2009 \\
\hline \multirow[t]{2}{*}{ North area of the Bohai Bay } & Range & $1.02-13.68$ & $1.92-2.96$ & $0.01-0.22$ & $0.43-0.63$ & & $0.31-0.78$ & $1.01-1.52$ & Jiang et al., 2005 \\
\hline & Mean & 3.43 & 2.22 & 0.05 & 0.53 & & 0.43 & 1.22 & \\
\hline Rushan Bay & Range & $0.94-8.94$ & & & & & & & Wang et al., 2008 \\
\hline
\end{tabular}

BDL: below detection limit. 
Table 2

Spearman correlation coefficients between the measured parameters.

\begin{tabular}{|c|c|c|c|c|c|c|c|c|c|c|c|c|c|c|}
\hline & [AVS] & [SEM] & $\mathrm{Cd}$ & $\mathrm{Cu}$ & $\mathrm{Ni}$ & $\mathrm{Pb}$ & $\mathrm{Zn}$ & $\mathrm{pH}$ & Eh & \%Clay & \%Silt & $\%$ Sand & \%ТOC & $\%$ Water content \\
\hline [AVS] & 1 & 0.259 & -0.221 & 0.171 & 0.310 & 0.235 & 0.271 & 0.172 & $-0.468^{c}$ & 0.278 & 0.180 & -0.210 & 0.130 & 0.018 \\
\hline [SEM] & 0.259 & 1 & $0.564^{\mathrm{b}}$ & $0.968^{\mathrm{a}}$ & $0.961^{\mathrm{a}}$ & $0.988^{\mathrm{a}}$ & $0.991^{\mathrm{a}}$ & $-0.483^{c}$ & -0.302 & $0.869^{\mathrm{a}}$ & $0.873^{\mathrm{a}}$ & $-0.902^{\mathrm{a}}$ & $0.856^{\mathrm{a}}$ & $0.790^{\mathrm{a}}$ \\
\hline Cd & -0.221 & $0.564^{b}$ & 1 & $0.573^{b}$ & $0.478^{c}$ & $0.564^{\mathrm{b}}$ & $0.567^{\mathrm{b}}$ & -0.375 & 0.143 & $0.401^{\mathrm{c}}$ & $0.429^{c}$ & $-0.437^{c}$ & $0.597^{\mathrm{b}}$ & $0.601^{\mathrm{b}}$ \\
\hline $\mathrm{Cu}$ & 0.171 & $0.968^{\mathrm{a}}$ & $0.573^{\mathrm{b}}$ & 1 & $0.945^{\mathrm{a}}$ & $0.958^{\mathrm{a}}$ & $0.930^{\mathrm{a}}$ & $-0.507^{b}$ & -0.323 & $0.888^{\mathrm{a}}$ & $0.856^{\mathrm{a}}$ & $-0.893^{\mathrm{a}}$ & $0.869^{\mathrm{a}}$ & $0.773^{\mathrm{a}}$ \\
\hline $\mathrm{Ni}$ & 0.310 & $0.961^{\mathrm{a}}$ & $0.478^{\mathrm{c}}$ & $0.945^{\mathrm{a}}$ & 1 & $0.922^{\mathrm{a}}$ & $0.926^{\mathrm{a}}$ & $-0.531^{b}$ & -0.380 & $0.885^{\mathrm{a}}$ & $0.890^{\mathrm{a}}$ & $-0.918^{\mathrm{a}}$ & $0.798^{\mathrm{a}}$ & $0.729^{\mathrm{a}}$ \\
\hline $\mathrm{Pb}$ & 0.235 & $0.988^{\mathrm{a}}$ & $0.564^{\mathrm{b}}$ & $0.958^{\mathrm{a}}$ & $0.922^{\mathrm{a}}$ & 1 & $0.984^{\mathrm{a}}$ & $-0.443^{c}$ & -0.281 & $0.847^{\mathrm{a}}$ & $0.834^{\mathrm{a}}$ & $-0.866^{\mathrm{a}}$ & $0.857^{\mathrm{a}}$ & $0.788^{\mathrm{a}}$ \\
\hline $\mathrm{Zn}$ & 0.271 & $0.991^{\mathrm{a}}$ & $0.567^{\mathrm{b}}$ & $0.930^{\mathrm{a}}$ & $0.926^{\mathrm{a}}$ & $0.984^{\mathrm{a}}$ & 1 & $-0.445^{c}$ & -0.262 & $0.829^{a}$ & $0.848^{\mathrm{a}}$ & $-0.872^{\mathrm{a}}$ & $0.840^{\mathrm{a}}$ & $0.787^{\mathrm{a}}$ \\
\hline
\end{tabular}

a $P<0.001$.

b $0.001<P<0.01$.

c $0.01<P<0.05$.

sufficient quantities, because the potentially bioavailable metals could be sequestered to form particulate phase and become biologically harmless during the AVS precipitation of the dissolved metals present in pore water. On the contrary, the excess of metals could potentially go into pore water as free ions and cause toxicity to the benthic fauna if there are no sufficient sulfide ions available. Therefore, the relationship between the molar concentration of AVS ([AVS], $\mu \mathrm{mol} \mathrm{g}^{-1}$ ) and the corresponding SEM ( $[\mathrm{SEM}], \mu \mathrm{mol} \mathrm{g}^{-1}$ ) has been proposed as a possible indicator of metal toxicity in anaerobic sediments (Ankley et al., 1994; Berry et al., 1996; Long et al., 1998; Liu et al., 2010). According to the theory above, no acute toxic effects of metals in sediments are expected when [SEM] $-[\mathrm{AVS}]<0$ or [SEM] $/$ [AVS] $<1$, which was the case for all the samples from the NYS except three, i.e. those from the sampling sites 14, 16 and 25 as shown in Fig. 3c. For the BS (Fig. 3c), reverse to the condition of the NYS, the results indicated that 8 among the 13 values were higher than the value which indicates that the concentrations of metals in sediments may have potential negative effects on surrounding ecosystem, namely [SEM] - [AVS] > 0 (Di Toro et al., 1992; Berry et al., 1996). The [SEM] / [AVS] ratios in the BS and the NYS were within the ranges of $0.13-2.15$ and $0.17-1.26$ with the averages of $1.23 \pm 0.62$ and $0.57 \pm 0.39$ (mean \pm standard deviation), respectively.

According to USEPA (2004), the quality of a sediment falls into one of the following three tiers: Tier 1, adverse effects on aquatic life are probable when [SEM] - [AVS] $>5 \mu \mathrm{mol} \mathrm{g}^{-1}$; Tier 2, adverse effects on aquatic life are possible when $0 \mu \mathrm{mol} \mathrm{g}^{-1}<$ [SEM] - [AVS] $<$ $5 \mu \mathrm{mol} \mathrm{g}{ }^{-1}$; Tier 3, there is no indication of adverse effects when [SEM] - [AVS] $<0 \mu \mathrm{mol} \mathrm{g}^{-1}$. Based on this criteria, the surface sediments of the sampling sites 14, 16 and 25 belonged to Tier 2 with possible associated adverse effects, while those of the other sampling sites belonged to Tier 3 and had no adverse effects on aquatic life in the NYS (Fig. 3c). In contrast, in the BS, only the 5 samples from the sampling sites 2, 4, 5, 9 and 13 fitted into Tier 3 and the rest fitted into Tier 2 (Fig. 3c).

In addition to AVS, the organic carbon in sediment is also an important controlling factor for the potential mobility of trace metals. Therefore, the biological risks of some sediments with [SEM] [AVS] $>0 \mu \mathrm{mol} \mathrm{g}^{-1}$ might be overestimated in some conditions (Burton Jr et al., 2005; Di Toro et al., 2005; Brix et al., 2010). To improve the accuracy in the prediction of sediment toxicity using the relationship between [SEM] and [AVS], a complementary evaluation method taking into account the TOC concentration $\left(f_{\mathrm{OC}}\right)$ has been proposed in USEPA (2005). Based on this criterion, the quality of a sediment falls into one of the following three tiers: Tier 1, associated adverse effects on aquatic life are probable when ([SEM] - [AVS]) / $f_{\mathrm{OC}}>3000 \mu \mathrm{mol} \mathrm{g}^{-1} \mathrm{OC}$; Tier 2 , associated adverse effects on aquatic life are possible when $130 \mu \mathrm{mol} \mathrm{g}^{-1}$ OC < ([SEM] - [AVS]) / $f_{\mathrm{OC}}<3000 \mu \mathrm{mol} \mathrm{g}^{-1} \mathrm{OC}$; Tier 3 , there is no indication of associated adverse effects when ([SEM] - [AVS]) $/ f_{\mathrm{OC}}<130 \mu \mathrm{mol} \mathrm{g}{ }^{-1}$ OC (USEPA, 2005). Accordingly, all of the samples in this study had ([SEM] - [AVS]) $/ f_{\mathrm{OC}}<130 \mu \mathrm{mol} \mathrm{g}^{-1} \mathrm{OC}$, putting them in sediment quality Tier 3. Like that of the [SEM] - [AVS] values, only 3 of the 11 positive ([SEM] $-[\mathrm{AVS}]) / f_{\mathrm{OC}}$ values were recorded in the NYS, and two thirds of the 15 negative ([SEM] - [AVS]) / $f_{\mathrm{OC}}$ values, in contrast, were recorded in the NYS (Fig. 3d). In other words, their average in the BS was higher than that in the NYS.

In summary, the results of this research indicated that the surface sediments of the BS had a slightly lower mean AVS concentration than those of the NYS, while the opposite was true in terms of the mean SEM concentrations. Among the measured environmental parameters, SEM could be likely influenced by more factors including grain size composition, TOC, water content and $\mathrm{pH}$ than AVS which was solely significantly correlated with the redox potential values of the sediments. On average, the concentrations of the SEM components increased in the order $\mathrm{Cd}<<\mathrm{Pb}<\mathrm{Ni}<\mathrm{Cu}<\mathrm{Zn}$ in the BS, and they followed the order $\mathrm{Cd}<<\mathrm{Pb}<\mathrm{Cu}<\mathrm{Ni}<\mathrm{Zn}$ in the NYS. Reflected by the relationship between AVS and SEM, comparatively, the surface sediments of the NYS were in better quality and not to cause negative effects on its ecosystem than that of the BS; however, the surface sediments of both the BS and the NYS were in good quality status when the

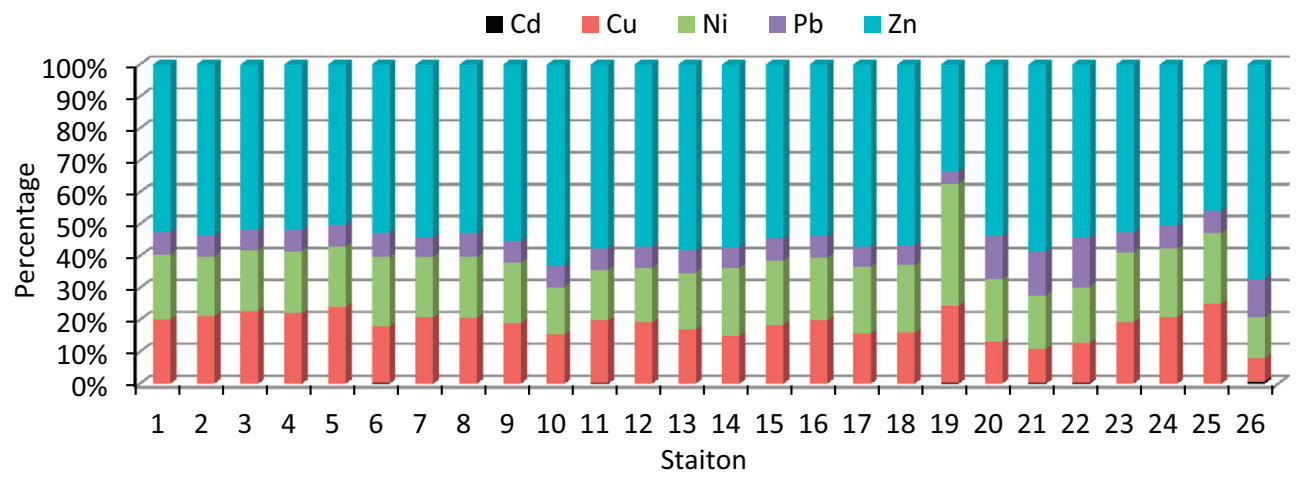

Fig. 4. Spatial distribution of relative concentrations of SEM components. 
influence of TOC on the potential mobility of the metals was considered.

\section{Declaration of Competing Interests.}

The authors declare that they have no known competing financial interests or personal relationships that could have appeared to influence the work reported in this paper.

\section{CRediT authorship contribution statement}

Xuelu Gao:Conceptualization, Resources, Writing - original draft.Jinming Song:Writing - review \& editing.Xuegang Li:Writing review \& editing.Huamao Yuan:Writing - review \& editing.Jianmin Zhao:Funding acquisition, Writing - review \& editing.Qianguo Xing:Writing - review \& editing.Peimiao Li:Investigation.

\section{Acknowledgments}

This study was financially supported by the Strategic Priority Research Program of the Chinese Academy of Sciences (XDA23050303) and the National Natural Science Foundation of China (41376083).

\section{References}

Allen, H.E., Fu, G., Deng, B., 1993. Analysis of acid-volatile sulfide (AVS) and simultaneously extracted metals (SEM) for the estimation of potential toxicity in aquatic sediments. Environ. Toxicol. Chem. 12, 1441-1453.

Ankley, G.T., Thomas, N., Di Toro, D.M., Hansen, D.J., Mahony, J.D., Berry, W.J., Swartz, R., Hoke, R., Garrison, A., Allen, H., Zarba, C., 1994. Assessing potential bioavailability of metals in sediments: a proposed approach. Environ. Manag. 18, 331-337.

Ankley, G.T., Di Toro, D.M., Hansen, D.J., Berry, W.J., 1996. Technical basis and proposal for deriving sediment quality criteria for metals. Environ. Toxicol. Chem. 15, 2056-2066.

Berry, W.J., Hansen, D.J., Mahony, J.D., Robson, D.L., Di Toro, D.M., Shipley, B.P., Rogers, B., Corbin, J.M., Boothman, W.S., 1996. Predicting the toxicity of metalspiked laboratory sediments using acid-volatile sulfide and interstitial water normalizations. Environ. Toxicol. Chem. 15, 2067-2079.

Brix, K.V., Keithly, J., Santore, R.C., DeForest, D.K., Tobiason, S., 2010. Ecological risk assessment of zinc from stormwater runoff to an aquatic ecosystem. Sci. Total Environ. 408, 1824-1832.

Brouwer, H., Murphy, T.P., 1994. Diffusion method for the determination of acid-volatile sulphides (AVS) in sediment. Environ. Toxicol. Chem. 13, 1273-1275.

Bryan, G.W., Waldichuk, M., Pentreath, R.J., Darracott, A., 1979. Bioaccumulation of marine pollutants. Philosophical Transactions of the Royal Society of London B: Biological Sciences 286, 483-505.

Burton Jr., G.A., Nguyen, L.T.H., Janssen, C., Baudo, R., Mcwilliam, R., Bossuyt, B. Beltrami, M., Green, A., 2005. Field validation of sediment zinc toxicity. Environ. Toxicol. Chem. 24, 541-553.

Chen, Y., Ge, J., Huang, T., Shen, L., Chu, Z., Xie, Z., 2020. Restriction of sulfate reduction on the bioavailability and toxicity of trace metals in Antarctic lake sediments. Mar. Pollut. Bull. 151, 110807.

Di Toro, D.M., Mahony, J.D., Hansen, D.J., Scott, K.J., Hicks, M.B., Mayr, S.M., Redmond, M.S., 1990. Toxicity of cadmium in sediments: the role of acid volatile sulfide. Environ. Toxicol. Chem. 9, 1487-1502.

Di Toro, D.M., Mahony, J.D., Hansen, D.J., Scott, K.J., Carlson, A.R., Ankley, G.T., 1992. Acid volatile sulfide predicts the acute toxicity of cadmium and nickel in sediments. Environ. Sci. Technol. 26, 96-101.

Di Toro, D.M., McGrath, J.A., Hansen, D.J., Berry, W.J., Paquin, P.R., Mathew, R., Wu, K.U., Santore, R.C., 2005. Predicting sediment metal toxicity using a sediment biotic ligand model: methodology and initial application. Environ. Toxicol. Chem. 24, 2410-2427.

Du, H., Huang, X.B., Huang, H.H., Zheng, B., Chen, W.Z., 2011. The spatiotemporal distribution of acid-volatile sulfide (AVS) and sulfate-reducing bacteria (SRB) in the surface deposits at Shen'ao bay. Transactions of Oceanology and Limnology 85-93 (in Chinese).

Fang, T., Li, X.D., Zhang, G., 2005. Acid volatile sulfide and simultaneously extracted metals in the sediment cores of the Pearl River estuary, South China. Ecotoxicol. Environ. Saf. 61, 420-431.

Gao, X.L., Li, P.M., Chen, C.T.A., 2013. Assessment of sediment quality in two important areas of mariculture in the Bohai Sea and the northern Yellow Sea based on acidvolatile sulfide and simultaneously extracted metal results. Mar. Pollut. Bull. 72, 281-288.

Gao, X.L., Zhou, F.X., Chen, C.T.A., 2014. Pollution status of the Bohai Sea: an overview of the environmental quality assessment related trace metals. Environ. Int. 62, 12-30.

Gao, X.L., Zhuang, W., Chen, C.T.A., Zhang, Y., 2015. Sediment quality of the SW coastal Laizhou Bay, Bohai Sea, China: a comprehensive assessment based on the analysis of heavy metals. PLoS One 10 (3), e0122190.

Hansen, D.J., Berry, W.J., Boothman, W.S., Di Toro, D.M., Robson, D.L., 1996. Predicting the toxicity of metal-contaminated field sediments using interstitial concentration of metals and acid-volatile sulfide normalizations. Environ. Toxicol. Chem. 15, 2080-2094.

Hsieh, Y.P., Shieh, Y.N., 1997. Analysis of reduced inorganic sulfur by diffusion methods: improved apparatus and evaluation for sulfur isotopic studies. Chem. Geol. 137,
255-261.

Hsieh, Y.P., Yang, C.H., 1989. Diffusion methods for the determination of reduced inorganic sulfur species in sediments. Limnol. Oceanogr. 34, 1126-1 130.

Huo, W.Y., Li, Q.S., Ma, X.N., 2001. Study on acid-volatile sulfide (AVS) of sediment in mariculture region of Jiaozhou Bay. Sci. Geogr. Sin. 21, 135-139 (in Chinese).

Jiang, Z.H., Ma, Q.M., Wang, X.L., Zhang, Y.Y., 2005. Study on the AVS in surface sediment in the north area of the Bohai Bay. Mar. Environ. Sci. 24 (7-8), 43 (in Chinese).

Lasorsa, B., Casas, A., 1996. A comparison of sample handling and analytical methods for determination of acid volatile sulfides in sediment. Mar. Chem. 52, 211-220.

Leonard, E.N., Cotter, A.M., Ankley, G.T., 1996. Modified diffusion method for analysis of acid volatile sulphides and simultaneously extracted metals in freshwater sediment. Environ. Toxicol. Chem. 15, 1479-1481.

Li, L., Wang, X., Liu, J., Shi, X., Ma, D., 2014a. Assessing metal toxicity in sediments using the equilibrium partitioning model and empirical sediment quality guidelines: a case study in the nearshore zone of the Bohai Sea, China. Mar. Pollut. Bull. 85, 114-122.

Li, L., Wang, X., Zhu, A., Yang, G., Liu, J., 2014b. Assessing metal toxicity in sediments of Yellow River wetland and its surrounding coastal areas, China. Estuar. Coast. Shelf Sci. 151, 302-309.

Liu, J., Yan, C., Macnair, M.R., Hu, J., Li, Y., 2007. Vertical distribution of acid-volatile sulfide and simultaneously extracted metals in mangrove sediments from the Jiulong River estuary, Fujian, China. Environ. Sci. Pollut. Res. 14, 345-349.

Liu, J.C., Yan, C.L., Kate, L.S., Zhang, R.F., Lu, H.L., 2010. The distribution of acid-volatile sulfide and simultaneously extracted metals in sediments from a mangrove forest and adjacent mudflat in Zhangiiang estuary, China. Mar. Pollut. Bull. 60, 1209-1216.

Long, E.R., Field, L.J., Mac Donald, D.D., 1998. Predicting toxicity in marine sediments with numerical sediment quality guidelines. Environ. Toxicol. Chem. 17, 714-727.

Machado, W., Santelli, R.E., Carvalho, M.F., Molisani, M.M., Barreto, R.C., Lacerda, L.D., 2008. Relation of reactive sulfides with organic carbon, iron, and manganese in anaerobic mangrove sediments: implications for sediment suitability to trap trace metals. J. Coast. Res. 24 (4A), 25-32.

Pan, K., Wang, W.X., 2012. Trace metal contamination in estuarine and coastal environments in China. Sci. Total Environ. 421, 3-16.

Pignotti, E., Guerra, R., Covelli, S., Fabbri, E., Dinelli, E., 2018. Sediment quality assessment in a coastal lagoon (Ravenna, NE Italy) based on SEM-AVS and sequential extraction procedure. Sci. Total Environ. 635, 216-227.

Prica, M., Dalmacija, B., Rončević, S., Krčmar, D., Bečelić, M., 2008. A comparison of sediment quality results with acid volatile sulfide (AVS) and simultaneously extracted metals (SEM) ratio in Vojvodina (Serbia) sediments. Sci. Total Environ. 389, 235-244.

Rickard, D., Morse, J.W., 2005. Acid volativle sulfide (AVS). Mar. Chem. 97, 141-197.

Sahuquillo, A., Rigol, A., Rauret, G., 2003. Overview of the use of leaching/extraction tests for risk assessment of trace metals in contaminated soils and sediments. Trends Anal. Chem. 22, 152-159.

Shepard, F.P., 1954. Nomenclature based on sand-silt-clay ratios. J. Sediment. Petrol. 24, 151-158.

USEPA (United States Environmental Protection Agency), 2004. The Incidence and Severity of Sediment Contamination in Surface Waters of the United States, National Sediment Quality Survey, Second edition. U.S. Environmental Protection Agency, Office of Water, Washington, DC EPA 823-R-04-007.

USEPA (United States Environmental Protection Agency), 2005. Procedures for the Derivation of Equilibrium Partitioning Sediment Benchmarks (ESBs) for the Protection of Benthic Organisms: Metal Mixtures (Cadmium, Copper, Lead, Nickel, Silver, and Zinc). United States Environmental Protection Agency, Office of Research and Development, EPA-600-R-02-011, Washington, DC.

van den Berg, G.A., Gustav Loch, J.P., van der Heijdt, L.M., Zwolsman, J.J.G., 1999. Mobilisation of heavy metals in contaminated sediments in the River Meuse, the Netherlands. Water Air Soil Pollut. 116, 567-586.

van den Hoop, M.A.G.T., den Hoop, H.A., Kerdijk, H.N., 1997. Spatial and seasonal variation of acid-volatile sulfide (AVS) and simultaneously extracted metals (SEM) in Dutch marine and freshwater sediments. Chemosphere 35, 2307-2316.

van Griethuysen, C., Gillissen, F., Koelmans, A.A., 2002. Measuring acid volatile sulphide in floodplain lake sediments: effect of reaction time, sample size and aeration. Chemosphere 47, 395-400.

Wang, Q., Qu, K.M., Ma, S.A., Song, Y.L., 2008. Distribution and variation of AVS in the sediments of Rushan Bay. Marine Fisheries Research 29, 102-107 (in Chinese).

Wang, W.X., 2002. Interactions of trace metals and different marine food chains. Mar. Ecol. Prog. Ser. 243, 295-309.

Wang, Z., Yin, L., Qin, X., Wang, S., 2019. Integrated assessment of sediment quality in a coastal lagoon (Maluan Bay, China) based on AVS-SEM and multivariate statistical analysis. Mar. Pollut. Bull. 146, 476-487.

Wilson, D.J., Chang, E., 2000. Bioturbation and oxidation of sulfide in sediments. Journal of the Tennessee Academy of Science 75, 76-85.

Wu, Q.Q., Ma, Q.M., Wang, J.G., Jiang, Z.H., Wang, X.L., 2007. The AVS in surface sediment of near sea area of Huanghe estuary. Mar. Environ. Sci. 26, 126-129 (in Chinese).

Ye, S.Y., Laws, E.A., Zhong, S.J., Ding, X.G., Pang, S.J., 2011. Sequestration of metals through association with pyrite in subtidal sediments of the Nanpaishui estuary on the Western Bank of the Bohai Sea, China. Mar. Pollut. Bull. 62, 934-941.

Yu, W.Q., Zhong, S.J., Pu, X.Q., Liu, F., 2009. Environmental responses of total organic carbon (TOC), acid volatile sulfide (AVS) and heavy metal elements in sediments of Licun estuary in Jiaozhou Bay. J. Palaeogeogr. 11, 338-347 (in Chinese).

Zhang, Y., Song, J.M., Yuan, H.M., Xu, Y.Y., He, Z.P., 2010. Concentrations of cadmium and zinc in seawater of Bohai Bay and their effects on biomarker responses in the bivalve Chlamys farreri. Arch. Environ. Contam. Toxicol. 59, 120-128.

Zhuang, W., Gao, X.L., 2013. Acid-volatile sulfide and simultaneously extracted metals in surface sediments of the southwestern coastal Laizhou Bay, Bohai Sea: concentrations, spatial distributions and the indication of heavy metal pollution status. Mar. Pollut. Bull. 76, 128-138. 